4 European Association For The Study Of The Liver, European Organisation For Research And Treatment Of Cancer. EASLEORTC clinical practice guidelines: management of hepatocellular carcinoma. J Hepatol 2012;56:908-43.

5 Spreafico C, Maccauro M, Mazzaferro V, Chiesa C. The dosimetric importance of the number of ${ }^{90} \mathrm{Y}$ microspheres in liver transarterial radioembolization (TARE). Eur J Nucl Med Mol Imaging 2014:41:634-38.

6 Sharma RA, Van Hazel GA, Morgan B et al. Radioembolization of liver metastases from colorectal cancer using yttrium-90 microspheres with concomitant systemic oxaliplatin, fluorouracil, and leucovorin chemotherapy. J Clin Oncol 2007;25:1099-106.

7 Van Hazel G, Blackwell A, Anderson J. Randomised phase 2 trial of SIR-Spheres plus fluorouracil/leucovorin chemotherapy versus fluorouracil/leucovorin chemotherapy alone in advanced colorectal cancer. J Surg Oncol 2004:88:78-85.

8 Hendlisz A, Van den Eynde M, Peeters M. Phase III trial comparing protracted intravenous fluorouracil infusion alone or with yttrium-90 resin microspheres radioembolization for liver-limited metastatic colorectal cancer refractory to standard chemotherapy. J Clin Oncol 2010:28:3687-94.

9 von Hazel GA, Heinemann V, Sharma NK. SIRFLOX: randomized phase III trial comparing first-line mFOLFOX6 (Plus or Minus Bevacizumab) versus mFOLFOX6 (plus or minus bevacizumab) plus selective internal radiation therapy in patients with metastatic colorectal cancer. J Clin Oncol 2016:34:1723-31.

10 Buscombe JR. Selective internal radiation therapy in metastatic carcinoma of the colon: a story of nonintegrated care? World J Nucl Med 2016:15:79-80.

11 Sharma RA, Wasan HS, Love SB. FOXFIRE: a phase III clinical trial of chemo-radio-embolisation as first-line treatment of liver metastases in patients with colorectal cancer. Clin Oncol ( $R$ Coll Radiol) 2008;20:261-3.
12 Salem R, Lewandowski RJ, Kulik L. Radioembolization results in longer time-to-progression and reduced toxicity compared with chemoembolization in patients with hepatocellular carcinoma. Gastroenterology 2011;140:497-507.

13 Winter H, Boardman P, Morgan D, Greenhalgh T, Sharma R. Advances in selective internal radiotherapy for primary and secondary liver cancer. RAD magazine 2016;42(496):17-8.

14 National Institute for Health and Care Excellence. Selective internal radiation therapy for non-resectable colorectal metastases in the liver. NICE interventional procedures guidance No 401. London: NICE, 2013.

15 National Institute for Health and Care Excellence. Selective internal radiation therapy for primary hepatocellular carcinoma. NICE interventional procedures guidance No 460. London: NICE, 2013.

16 National Institute for Health and Care Excellence. Selective internal radiation therapy for primary intrahepatic cholangiocarcinoma. NICE interventional procedures guidance No 459. London: NICE, 2013.

17 National Institute for Health and Care Excellence. TheraSphere for treating operable and inoperable hepatocellular carcinoma. NICE medtech innovation briefing No 62. London: NICE, 2016.

18 National Institute for Health and Care Excellence. SIR-Spheres for treating inoperable hepatocellular carcinoma. NICE medtech innovation briefing No 63. London: NICE, 2016.

19 NHS England. NHS England announces hospitals chosen to take part in new initiative aimed at increasing access to radiotherapy. Leeds: NHS England, 2013. www.england.nhs.uk/2013/11/sirt-comm/ [Accessed 26 July 2017].

Address for correspondence: Dr Francis X Sundram, Department of Nuclear Medicine, MP 26, Southampton General Hospital, Tremona Road, Southampton S016 6YD, UK. Email: francis.sundram@uhs.nhs.uk

\title{
Molecular radiotheragnostics in thyroid disease
}

\author{
Authors: Nitasha Singh ${ }^{A}$ and Val Lewington ${ }^{B}$
}

\begin{abstract}
Molecular radiotheragnostics directly links nuclear medicine diagnostic imaging to therapy. The imaging study is used to detect a specific molecular target associated with a disease process. A radiotherapeutic molecule with a similar biodistribution to the diagnostic agent can then be used to deliver targeted therapy.

Molecular radiotheragnostics have been applied to manage both benign and malignant thyroid disease since the 1940s. The specific molecular pathway targeted is the sodium/iodide symporter (NIS) located on the basolateral membrane of the thyroid follicular cell. Radiolabelling of iodide or a similar ion
\end{abstract}

Authors: ${ }^{\text {A }}$ consultant in nuclear medicine, Brighton and Sussex

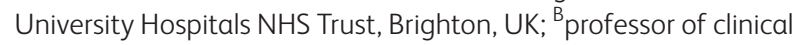
therapeutic nuclear medicine, Kings College London, London, UK allows targeting of the NIS system with radiopharmaceuticals for imaging ( ${ }^{123} \mathrm{I}$-radioiodine and ${ }^{99 \mathrm{~m}} \mathrm{Tc}$-pertechnetate) and treatment ( ${ }^{131} \mathrm{I}$-radioiodine) by virtue of their gamma ray and beta-particle emissions, respectively.

Scintigraphic imaging directly guides ${ }^{131}$ I-radioiodine treatment planning to maximise therapeutic benefit while minimising adverse reactions, in a personalised medicine approach.

\section{Principles}

Molecular radiotheragnostics combine nuclear medicine diagnostic imaging with treatment. Imaging is used to detect a specific molecular target associated with an underlying disease process. A radiotherapeutic molecule with a similar biodistribution to the imaging radiopharmaceutical can then be used to deliver targeted therapy. ${ }^{1}$ 
Molecular radiotheragnostics have been applied to thyroid disease since the 1940s when radioiodine was first used to treat thyroid disorders. ${ }^{1}$ Subsequent gamma camera development in the 1950 s then made imaging possible. ${ }^{2}$ The specific molecular pathway targeted is the sodium/iodide symporter (NIS). NISmediated iodide accumulation within the thyroid is central to molecular thyroid theragnostics. Radiolabelling of iodide or similar ions allows targeting of the NIS-system for imaging and therapy. ${ }^{1}$

\section{The sodium/iodide symporter}

Iodine is essential for the synthesis of the thyroid hormones thyroxine (T4) and triiodothyronine (T3). Iodide ions are taken up by the NIS, a basolateral transmembrane protein on the thyroid follicular cells that actively co-transports sodium and iodide ions into cells against a concentration gradient. ${ }^{3}$ Iodide is then translocated across the apical cell membrane and oxidised by thyroid peroxidase. Iodination of the tyrosine residues of thyroglobulin (colloid protein) then takes place (organification). Thyroglobulin is the precursor of thyroid hormone synthesis.

NIS expression is upregulated by thyroid-stimulating hormone (TSH) and downregulated by thyroglobulin and antithyroid medications. NIS is also expressed by non-thyroidal tissues, eg salivary and lacrimal glands, stomach, lactating breast, placenta, kidneys and thymus. ${ }^{4,5}$

\section{Thyroid theragnostic radiopharmaceuticals}

Theragnostic radiopharmaceuticals emit ionising radiation as gamma rays and/or beta-particles, allowing scintigraphic imaging and therapy, respectively (Table 1). The NIS-system can be targeted specifically using radioactive iodide (I) or pertechnetate ions, which share similar chemical properties.

\section{Key points}

Molecular radiotheragnostics use nuclear medicine diagnostic imaging to detect a specific molecular target. A radiotherapeutic molecule with a similar bio-distribution can then be used to deliver targeted therapy

In thyroid disease, the specific molecular pathway targeted is the sodium/iodide symporter (NIS)

NIS-mediated iodide (or a similar ion) accumulation within the thyroid is central to molecular theragnostics in both benign and malignant thyroid disease

$99 \mathrm{~m}$ Tc-pertechnetate and ${ }^{123} \mathrm{I}$-radioiodine are used for imaging and ${ }^{131} \mathrm{I}$-radioiodine for treatment. ${ }^{99 \mathrm{~m}} \mathrm{Tc}$-pertechnetate is not the imaging agent of choice for thyroid cancer imaging

Imaging is useful to plan therapy and optimise a personalised medicine approach

KEYWORDS: ${ }^{99 \mathrm{~m}} \mathrm{Tc}$-pertechnetate, DTC (differentiated thyroid cancer), molecular, NIS (sodium/iodide symporter), radioiodine, radiotheragnostic, thyroid, thyrotoxicosis
Labelled with the gamma-emitter technetium- $99 \mathrm{~m}\left({ }^{99 \mathrm{~m}} \mathrm{Tc}\right)$, pertechnetate ions are taken up via the NIS into thyroid follicular cells where they are trapped but not organified. ${ }^{6}$ ${ }^{99} \mathrm{~m}$ Tc-pertechnetate is the first-line scintigraphic diagnostic thyroid imaging agent for the investigation of benign thyroid disease, is readily available and is inexpensive. Reduced NIS expression by malignant thyroid cells leads to low pertechnetate uptake, giving a 'cold nodule' appearance.

${ }^{123}$ I-radioiodine decays by gamma ray emission and, unlike pertechnetate, is organified by the thyroid so can be used to characterise poorly functioning retrosternal thyroid tissue, for thyroid cancer imaging and for personalised treatment dose planning. Disadvantages include the relative cost, availability and 13-hour half-life.

${ }^{131}$ I-radioiodine has an 8 -day half-life and decays by gamma ray and beta-particle emission allowing both imaging and targeted therapy. ${ }^{131}$ I beta particles travel only short distances through tissue (average $0.4 \mathrm{~mm}$ ) and cause cell death directly by radiation-induced DNA damage or indirectly through freeradical formation.

\section{Benign thyroid disease}

Molecular radiotheragnostics in benign thyroid disease are applied in the imaging and treatment of

> hyperthyroidism due to solitary toxic nodule, toxic multinodular goitre or Graves' disease (relapsed or first-line treatment)

$>$ large non-toxic goitre to reduce gland volume in non-surgical candidates. $^{7}$

Scintigraphic imaging with ${ }^{99 \mathrm{~m}} \mathrm{Tc}$-pertechnetate or, less frequently, radioiodine provides visual assessment of activity distribution within the thyroid reflecting physiological and pathophysiological NIS-mediated iodide uptake. Imaging confirms the cause of hyperthyroidism and can be used to assess feasibility of ${ }^{131} \mathrm{I}$ as a therapeutic option and to guide activity prescription.

Anti-thyroid drugs, exogenous iodine, thyroxine and amiodarone all interfere with NIS-mediated thyroid radiopharmaceutical uptake and are withheld for varying periods before imaging (Table 2). ${ }^{8}$ Uptake of activity reflects metabolic function and may be quantified as a percentage of the administered activity to guide treatment.

Amplified follicular cell NIS expression in Graves' disease results in globally increased iodide uptake, shown as diffuse, increased radiopharmaceutical activity throughout the gland on imaging. Toxic multi-nodular glands show increased NIS expression in 'hot' hyperfunctioning nodules and reduced levels in 'cold' nodules. Increased NIS levels in autonomously functioning nodules manifest as increased radiopharmaceutical uptake within the nodule (Fig 1). ${ }^{9}$

Following the same NIS-uptake pathway, ${ }^{131}$ I can be used to deliver targeted beta-particle therapy. Treatment aims are to cure hyperthyroidism and achieve a euthyroid or hypothyroid state. ${ }^{7,10} \mathrm{UK}$ guidelines recommend fixed treatment activities between 400 and $800 \mathrm{MBq}$ depending on gland size, underlying aetiology and patient comorbidities. In practice, most patients receive $400-600 \mathrm{MBq}{ }^{11}$

Thyroid function is usually controlled with anti-thyroid drugs before treatment to reduce the risk of 'thyroid storm' 
Table 1. Properties of thyroid theragnostic radiopharmaceuticals

\begin{tabular}{|c|c|c|c|}
\hline \multirow[t]{2}{*}{ Properties } & \multicolumn{3}{|c|}{ Radiopharmaceutical } \\
\hline & ${ }^{131}$ I-radioiodine & ${ }^{123}$ I-radioiodine & 99m Tc-pertechnetate \\
\hline Production & Reactor & Cyclotron & Generator \\
\hline Half-life & $\begin{array}{l}8 \text { days (long half-life allows } \\
\text { transport some distance from } \\
\text { production) }\end{array}$ & $\begin{array}{l}13 \text { hours (longer half-life } \\
\text { allows transport some } \\
\text { distance from production) }\end{array}$ & $\begin{array}{l}6 \text { hours (short half- } \\
\text { life favours on site } \\
\text { production) }\end{array}$ \\
\hline Radioactive method of decay & Gamma ray and beta particles & Gamma ray & Gamma ray \\
\hline $\begin{array}{l}\text { Gamma ray energy peak ( } 140 \mathrm{KeV}=\text { ideal peak } \\
\text { for gamma camera imaging) }\end{array}$ & $364 \mathrm{KeV}$ & $159 \mathrm{KeV}$ & $140 \mathrm{KeV}$ \\
\hline Availability and expense & Easily available, cheap & $\begin{array}{l}\text { Less readily available } \\
\text { expensive }\end{array}$ & $\begin{array}{l}\text { Readily available, } \\
\text { cheap }\end{array}$ \\
\hline Radiation burden & High & Low & Lowest \\
\hline Uses & Imaging and therapy & Imaging & Imaging \\
\hline Uptake mechanism & $\begin{array}{l}\text { Physiological: both trapped } \\
\text { and organified }\end{array}$ & $\begin{array}{l}\text { Physiological: both trapped } \\
\text { and organified }\end{array}$ & $\begin{array}{l}\text { Mimics iodide: Trapped } \\
\text { but not organified }\end{array}$ \\
\hline Imaging time after diagnostic dose administration & $\begin{array}{l}\text { 18-24 hours (post-therapy } \\
\text { imaging at } 1-5 \text { days) }\end{array}$ & $2-6$ hours and $18-24$ hours & 20 minutes \\
\hline Potential for stunning & Yes & No & No \\
\hline
\end{tabular}

following therapy. These drugs should be withdrawn a few days before treatment because of their theoretical radio-protective effects. ${ }^{7}$ In patients with poorly functioning, non-toxic goitre, recombinant TSH is occasionally used to upregulate NIS and enhance ${ }^{131}$ I uptake.

Although radioiodine treatment for benign thyroid disease is outpatient based, patients are requested to follow simple radiation protection restrictions post-treatment. These are related to the activity of radioiodine received and may include a period of time off work depending on the nature of work, travel restrictions and avoidance of prolonged close contact with children and pregnant women. Premenopausal women should also avoid pregnancy for 6 months following radioiodine treatment. ${ }^{11}$

Fixed activity regimens offer the advantage of ease of clinical prescription, outcomes with respect to euthyroidism and hypothyroidism being dose dependent. Lower administered activities may reduce risks of hypothyroidism but carry an increased risk of treatment failure. Dosimetric approaches aiming to calculate a 'personalised' therapeutic dose of ${ }^{131} \mathrm{I}$ to achieve euthyroidism have not yet been shown to improve outcomes. $^{12}$

\section{Malignant thyroid disease}

Molecular radiotherapy plays a pivotal role in radio-sensitive differentiated papillary and follicular thyroid cancer (DTC) treatment. ${ }^{13}$ Thyroid cancer may present clinically as a nodule or, increasingly, as an incidental imaging finding. While thyroid nodules are common, thyroid cancer is rare (UK incidence $3.4 \times 10^{3}$ cases/annum). ${ }^{14,15}$

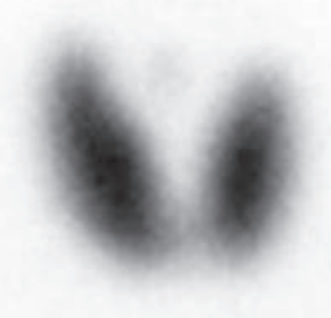

Fig 1. Scintigraphic imaging reflecting physiological and pathophysiological NISmediated iodide uptake in Graves' disease (A) and a toxic nodule (B). 
Table 2. Guidance times for withholding substances that may interfere with NIS-mediated thyroid radiopharmaceutical uptake prior to imaging

\begin{tabular}{|c|c|}
\hline Interfering substance & $\begin{array}{l}\text { Recommended time to withhold } \\
\text { prior to imaging }\end{array}$ \\
\hline Anti-thyroid drugs & $\begin{array}{l}\text { Pertechnetate imaging } \\
\text { Can be continued }{ }^{123} \text { I or }{ }^{131} \text { I 2-4 days }\end{array}$ \\
\hline Thyroxine $\left(T_{4}\right)$ therapy & 4-6 weeks \\
\hline $\begin{array}{l}\text { Triiodothyronine }\left(T_{3}\right) \\
\text { therapy }\end{array}$ & 2 weeks \\
\hline $\begin{array}{l}\text { Exogenous iodine (eg } \\
\text { water-soluble iodinated } \\
\text { contrast) }\end{array}$ & $6-8$ weeks \\
\hline Amiodarone & Greater than 6 months \\
\hline
\end{tabular}

DTCs are characterised by slow growth and favourable prognosis (80-95\% 10-year survival). Local disease recurrence in the thyroid surgical bed, cervical nodes or distant metastases is reported in $5-20 \%$ of patients, depending on primary staging, histological subtype and nodal involvement at diagnosis. ${ }^{16}$

Surgery and ${ }^{131}$ I therapy are the cornerstones of DTC management. Following total thyroidectomy, usually with loco-regional node dissection, ${ }^{131} \mathrm{I}$ is recommended to ablate normal thyroid remnant tissue, improve local disease control, increase the specificity of thyroglobulin (marker of tumour recurrence) and enable whole-body scintigraphy to identify occult metastases. TSH stimulation is used to upregulate NIS and maximise ${ }^{131}$ I uptake, either by post-thyroidectomy levothyroxine withdrawal or using recombinant human $\mathrm{TSH}^{13}$

Fixed activities are prescribed to ablate the thyroid remnant while minimising the risk of inducing a secondary cancer. Following publication of the HiLo study, the recommended activity for remnant ablation in the UK is $1.1 \mathrm{GBq}$ for lowrisk patients. Higher activities may be agreed for high-risk patients (nodal or distant metastases, extra-thyroidal tumour extension, R1 resection (microscopic residual tumour at the surgical resection margin) or primary tumour size $>4 \mathrm{~cm}$ ) following multidisciplinary meeting discussion. ${ }^{17}$ American and European guidelines recommend activities of 1.1-5.5 GBq for the treatment of metastases. ${ }^{13,18}$

Post-ablation ${ }^{131}$ I imaging performed $1-5$ days post-treatment is used to confirm remnant thyroid uptake and detect iodineavid metastases. Tomographic imaging fused with CT (single photon emission computerised tomography (SPECT)-CT), increases lesion detection sensitivity and provides accurate anatomical localisation. Having commenced post-ablation levothyroxine replacement to achieve TSH suppression, subsequent monitoring usually relies on ultrasound and thyroglobulin measurement. Further cycles of therapeutic ${ }^{131} \mathrm{I}$ may be required to treat persisting iodine-avid metastases.

Diagnostic ${ }^{123}$ I scintigraphy is sometimes helpful to detect occult disease, post thyroid remnant ablation, where other imaging has failed to identify the source of a rising thyroglobulin level. ${ }^{123}$ I avoids the risk of 'stunning' and is preferred to ${ }^{131} \mathrm{I}$ in patients who might proceed to further radioiodine treatment. Increasingly, however, ${ }^{123} \mathrm{I}$ has been superseded by ${ }^{18} \mathrm{~F}$-fluorodeoxyglucose (FDG) positron emission tomography (PET)-CT in patients with increasing thyroglobulin and non-iodine avid disease to exclude surgically resectable disease, followed by empirical ${ }^{131}$ I treatment.

Two-thirds of patients with metastatic disease become refractory to radioiodine because of tumour de-differentiation resulting in decreased NIS expression and/or targeting secondary to genetic alterations and dysregulation of signalling pathways. ${ }^{19}$ De-differentiated, recurrent iodine-negative lesions tend to have high glycolytic rates and are therefore FDG-avid. This inverse relationship between iodine and FDG-avidity (Fig 2), depending on differentiation, probably reflects tumour heterogeneity and importantly may result in a poor response to ${ }^{131}$ I treatment. Positive NIS-immunostaining could predict ${ }^{131} \mathrm{I}$ accumulation and, therefore, the effectiveness of treatment in recurrent lesions. ${ }^{20}$

Advances in molecular biology have identified specific molecular kinase pathways where oncogenic mutations have resulted in reduced NIS expression/targeting. ${ }^{21}$ Tyrosine kinase inhibitors (eg sorafenib) block these pathways, increasing NIS expression. The mitogen-activated protein kinase pathway inhibitor sulemetinib has also been shown to promote ${ }^{131} \mathrm{I}$ uptake in a small series of patients with iodine-refractory thyroid cancer, but this requires confirmation in larger studies. ${ }^{22}$ Re-differentiation therapies (eg retinoic acid) upgrade NIS and may restore ${ }^{131}$ I avidity. In some non-iodine avid thyroid
Fig 2. Inverse relationship between iodine and FDG avidity a reflection of tumour differentiation. A- ${ }^{131}$ I-radioiodine anterior neck image shows no iodine avid disease within the neck (salivary gland and nasal uptake is physiological); $\mathrm{B}-{ }^{18} \mathrm{~F}-\mathrm{FDG}$ PET-CT coronal fused image shows bilateral FDG-avid neck disease. CT = computerised tomography; FDG = fluorodeoxyglucose; $\mathrm{PET}=$ positron emission tomography

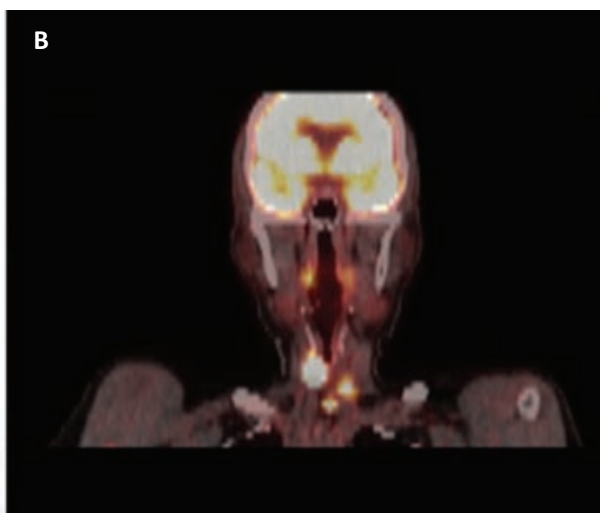


cancers the problem lies in NIS cell membrane translocation. Enhancing this may aid therapeutic ${ }^{131}$ I uptake. ${ }^{19}$ An alternative approach lies in detailed dosimetry planning to deliver a prescribed tumour radiation dose. Considering anatomical and uptake characteristics of each malignant lesion, dosimetrybased planning offers the opportunity to optimise treatment on an individual patient-basis, rather than administering fixed ${ }^{131}$ I activities. SPECT-CT technology is critical to undertaking 3-dimensional absorbed-dose calculations.

\section{Future directions}

${ }^{124}$ I is currently the only positron-emitting radioisotope of iodine that may have a role in molecular thyroid radiotheragnostics in the future. ${ }^{124}$ I-PET-CT has the potential advantage of superior image quality and might allow more accurate quantification to optimise prescribed amounts of therapeutic ${ }^{131} \mathrm{I}$.

Tumour heterogeneity, oxygenation and cell kinetics all affect dose-response relationships. Tumour apoptosis, hypoxia and cellular proliferation may be assessed by radioactive tracers, such as ${ }^{99 \mathrm{~m}} \mathrm{Tc}$-annexin $\mathrm{V},{ }^{18} \mathrm{~F}$-fluoromisonidazole and ${ }^{18} \mathrm{~F}$-fluorothymidine, and used to predict therapeutic response to ${ }^{131} \mathrm{I}$.

\section{Conclusions}

The established role of nuclear medicine imaging and therapy in managing benign and malignant thyroid disease is the oldest and, arguably, most successful example of molecular radiotheragnostics. The future lies in advances in molecular biology, the development of agents that increase NIS expression, dosimetry-based treatment planning and the introduction of novel PET radiopharmaceuticals, all of which have the potential to deliver the goal of a personalised medicine approach to thyroid disease.

\section{Conflicts of interest}

The authors have no conflicts of interest to declare.

\section{References}

1 Silberstein E. Radioiodine: the classic theranostic agent. Semin Nucl Med 2012;42:164-70.

2 Anger HO. Use of a gamma-ray pinhole camera for in vivo studies. Nature 1952;170:200-1.

3 Dai G, Levy O, Carrasco N. Cloning and characterisation of the thyroid iodide transporter. Nature 1996;379:458-60.

4 Smyth PP, Dwyer RM. The sodium iodide symporter and thyroid disease. Clin Endocrinol 2002;56:427-9.

5 Jong-Ryool O, Byeong-Cheol A. False positive uptake on radio-iodine whole body scintigraphy:physiologic and pathologic variants unrelated to thyroid cancer. Am J Nucl Med Mol Imaging 2012;2:362-5.
6 Orsini F, Lorenzoni A, Erba OA, Giuliano M. Radiopharmaceuticals for single photon emission imaging and for therapy. In: Strauss H, Mariani G, Volterrani D, Larson S (eds). Nuclear oncology. New York: Springer, 2013:24-5.

7 Stokkel M, Junak D, Lassmann M, Dietlein M, Luster M. EANM procedure guidelines for therapy of benign thyroid disease. Eur $J$ Nucl Med Mol Imaging 2010;37:2218-28.

8 Balon HR, Chair MD, Silberstein MD et al. Society of Nuclear Medicine procedure guideline for thyroid uptake measurement, version 3.0. Reston, VA: Society of Nuclear Medicine and Molecular Imaging, 2006.

9 Spitzweg C, Morris J. The sodium iodide symporter: its pathophysiological and therapeutic implications. Clin Endocrinol 2002;57:559-74.

10 Ross DS, Burch HB, Cooper DS et al. 2016 American Thyroid Association Guidelines for diagnosis and management of hyperthyroidism and other causes of thyrotoxicosis. Thyroid 2016;26:1343-421.

11 Royal College of Physicians. Radioiodine in the management of benign thyroid disease: clinical guidelines. Report of a Working Party. London: RCP, 2007.

12 McCready R. Radioiodine - the success story of nuclear medicine. Eur J Nucl Med Mol Imaging 2017;44:179-82.

13 Regalbuto C, Frasca F, Pellegriti G et al. Update on thyroid cancer treatment. Future Oncol 2012;8:1331-48.

14 Dean DS, Gharib H. Epidemiology of thyroid nodules. Best Pract Res Clin Endocrinol Metab 2008;22:901-11.

15 Cancer Research UK. Prostate cancer statistics. www.cancerresearchuk. org/health-professional/cancer-statistics/statistics-by-cancer-type/ prostate-cancer [Accessed 7 July 2017].

16 Chung J, Cheon GJ. Radioiodine therapy in differentiated thyroid cancer: the first targeted therapy in oncology. Endocrinol Metab 2014;29:233-9.

17 Perros P, Colley S, Boelaert K et al. Guidelines for the management of thyroid cancer. Clin Endocrinol 2014;81(Suppl 1):1-122.

18 Van Nostrand D, Atkins F, Yeganeh F et al. Dosimetrically determined doses of radio-iodine for the treatment of metastatic thyroid carcinoma. Thyroid 2002:12:121-34.

19 Byeong-Cheol A. Personalised medicine based on theranostic radioiodine molecular imaging for differentiated thyroid cancer. BioMed Res Int 2016;2016:1680464.

20 Mallick U, Harmer C, Yap B et al. Ablation with low-dose radioiodine and thyrotropin alfa in thyroid cancer. N Engl J Med 2012;366:167485 .

21 Wong K, Lang B. New molecular targeted therapy and redifferentiation therapy for radioiodine-refractory advanced papillary thyroid carcinoma: literature review. J Thyroid Res 2012;2012:818204.

22 Ho A, Grewal R, Leboeuf R et al. Selumetinib-enhanced radioiodine uptake in advanced thyroid cancer. $N$ Engl J Med 2013;368:623-32.

Address for correspondence: Dr Nitasha Singh, Brighton and Sussex University Hospitals NHS Trust, Eastern Road Brighton BN2 5BE, UK.

Email: Nitasha.Singh@bsuh.nhs.uk 